\title{
Knowledge about childhood bronchial asthma among primary health care personnel in eastern Saudi Arabia
}

\section{Attia ZainAlAbdeen Taha1, Amr Ahmed Sabra ${ }^{1}$, Jamal H. Al Hamed² \\ ${ }^{1}$ Department of Family and Community Medicine, College of Medicine, University of Dammam, Dammam, ${ }^{2}$ Ministry of Health, Primary Health Care Department, Eastern Province, Saudi Arabia}

Address for the Correspondence:

Dr. Attia Z. Taha, Department of Family and Community Medicine, College of Medicine, University of Dammam, P O Box 2114, Dammam-31451, Saudi Arabia. E-mail: attiaztaha@hotmail.com

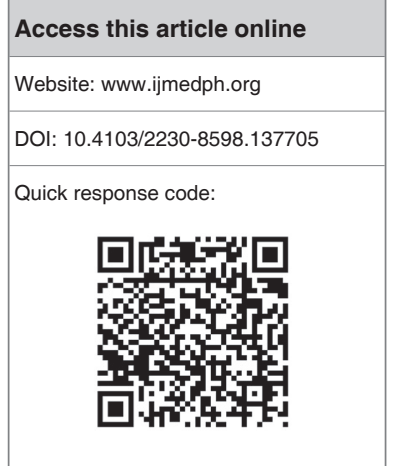

Background: Bronchial asthma (BA) is a chronic non-communicable disease affecting children and adults. Despite the availability of written guidelines for diagnosis and management, yet still knowledge and application were inadequate. The aim of this study was to assess asthma knowledge of primary health care centers (PHCCs) personnel in Dammam city, eastern Saudi Arabia. Materials and Methods: This was a cross-sectional study conducted in 22 PHCCs. The sample consisted of 194 personnel (50 physicians and 144 nurses). Data was collected through a self-administered questionnaire which contained 58 questions. Knowledge score about asthma was coded as good and poor. Descriptive statistics, paired t-test and logistic regression were used for statistical analysis. Results: The majority of PHCCs personnel $(96.9 \%)$ had no postgraduate studies and $78.4 \%$ of them didn't receive any training about BA. More than half $(55.2 \%)$ of the PHCCs personnel showed good total knowledge score about BA. Also, $81.8 \%$ of the physicians and $52.7 \%$ of the nurses had good total knowledge level regarding the total aspects of BA in children. Physicians had statistically higher mean knowledge score than nurses regarding all components and total knowledge scores. Knowledge about role of exercise and prognosis was inadequate. Being a physician, female, younger, less years of work in PHCCs were statistically significant and associated with good knowledge level. Conclusions: There are still some deficiencies in knowledge about different aspects related to bronchial asthma. It is recommended that both physicians and nurses receive training about national asthma guidelines through continuing medical education.

Key words: Bronchial asthma, childhood, knowledge, primary health care personnel, Saudi Arabia

\section{INTRODUCTION}

Bronchial asthma is a chronic non-communicable disease affecting both children and adults worldwide. ${ }^{[1-3]}$ Various studies in Kingdom of Saudi Arabia (KSA) showed an increasing prevalence in both urban and rural areas. ${ }^{[4]}$ The majority of asthma patients in KSA are managed by primary health care (PHC) physicians at primary health care centers (PHCCs). Knowledge of physicians about diagnosis and management of bronchial asthma is essential for better patient care. Several studies have assessed the knowledge of bronchial asthma among physicians and health care providers. ${ }^{[8-12]}$ Despite the availability of written protocols for diagnosis and management of bronchial asthma, yet still there is inadequate knowledge and application of these guidelines. ${ }^{[13-15]}$

The aim of this study was to assess the knowledge of PHCCs personnel (physicians and nurses) in Dammam city, eastern Saudi Arabia, and to determine factors affecting their knowledge.

\section{MATERIALS AND METHODS}

\section{Study design and sample size}

This was a cross-sectional study conducted in all the 22 PHCCs of the Dammam city, Eastern Province, Saudi Arabia, in the year 2010 during a two-months period. The study sample consisted of 194 PHC personnel (50 physicians and 144 nurses) working in the centers and agreed to share in the study. A 
pilot study was conducted to test the validity and the logistics of administering the questionnaire in one of the PHCCs. Personnel in the pilot study were excluded.

\section{Data collection}

Data collection was accomplished through a self-administered questionnaire constructed by the investigators. All the questions were close-ended and the questionnaire consisted of two main parts:

1. Personnel's socio-demographic characteristics: Occupation, nationality, gender, marital status, years of experience since graduation, duration of work in PHC, and training about bronchial asthma.

2. Fifty eight (58) questions to assess the knowledge about bronchial asthma in children divided into seven components namely; magnitude, definition and causes, risk factors, associated diseases, role of exercise, clinical picture, management, and prognosis.

A scoring system was used, giving a score of one to each correct answer and a score of zero to the wrong answers or do not know. The knowledge score was calculated by summation of the right answers, scores. The maximum total knowledge score was 58. The knowledge score of the components as well as the total knowledge score were divided into two groups namely, good and poor knowledge according to the cut-off points which were determined according to the mean of the distribution. Personnel who scored less than the cut-off point were considered as poor and those above the cut-off point were considered as good.

Necessary permissions to conduct the study were obtained from concerned authorities and confidentiality of the information was strictly adhered to by assuring the participants that no details about their status will be released and data will be only used for research purpose.

\section{Statistical analysis}

The collected data were reviewed, coded, verified and statistically analyzed using the Statistical Package for Social Sciences (SPSS) software version 16. Descriptive statistics for all studied variables and paired t-test were used. Logistic regression analysis was used to find the association between the characteristics of the PHCCs personnel (Independent variables) and the knowledge level about bronchial asthma (Dependant variable). A P-value level of $<0.05$ was considered significant throughout the study.

\section{RESULTS}

[Table 1] shows the socio-demographic characteristics of the PHC personnel. It was found that $77.4 \%$ of the personnel were nurses, females $(83 \%)$, Saudis $(90.2 \%)$, and $47.9 \%$ were in the age group 30 40 years. The majority of PHC personnel (96.9\%) had not undergone any postgraduate studies and $78.4 \%$ of them did not receive any training about bronchial asthma in children. More than half $(55.2 \%)$ of the PHC personnel showed good total knowledge score about

\begin{tabular}{|c|c|c|}
\hline \multirow[t]{2}{*}{ Socio-demographic characteristics } & \multicolumn{2}{|c|}{ Total $(n=194)$} \\
\hline & No. & $\%$ \\
\hline \multicolumn{3}{|l|}{ Occupation } \\
\hline Physicians & 44 & 22.6 \\
\hline Nurses & 150 & 77.4 \\
\hline \multicolumn{3}{|l|}{ Gender } \\
\hline Male & 33 & 17.0 \\
\hline Female & 161 & 83.0 \\
\hline \multicolumn{3}{|l|}{ Nationality } \\
\hline Saudi & 175 & 90.2 \\
\hline Non-Saudi & 19 & 9.8 \\
\hline \multicolumn{3}{|l|}{ Age in years } \\
\hline $20-30$ & 57 & 29.4 \\
\hline $30-40$ & 93 & 47.9 \\
\hline $40-50$ & 37 & 19.1 \\
\hline$\geq 50$ & 7 & 3.6 \\
\hline \multicolumn{3}{|l|}{ Mean Age in years $\pm S D=33.89 \pm 7.45$} \\
\hline \multicolumn{3}{|l|}{ Marital status } \\
\hline Single & 44 & 22.7 \\
\hline Married & 140 & 72.7 \\
\hline Divorced & 7 & 3.6 \\
\hline Widowed & 3 & 1.5 \\
\hline \multicolumn{3}{|l|}{ Years of Experience since graduation } \\
\hline$<5$ years & 53 & 27.3 \\
\hline $5-10$ & 38 & 19.6 \\
\hline$\geq 10$ & 103 & 53.1 \\
\hline \multicolumn{3}{|l|}{ Duration of work in $\mathrm{PHC}$} \\
\hline$<5$ years & 70 & 36.1 \\
\hline $5-10$ & 41 & 21.1 \\
\hline$\geq 10$ & 83 & 42.8 \\
\hline \multicolumn{3}{|l|}{ Postgraduate studies } \\
\hline None & 188 & 96.9 \\
\hline Diploma & 4 & 2.1 \\
\hline Fellowship & 2 & 1.0 \\
\hline \multicolumn{3}{|l|}{ Training about Bronchial asthma in children } \\
\hline$<1$ week duration & 40 & 20.6 \\
\hline$>1$ week duration & 2 & 1.0 \\
\hline No training & 152 & 78.4 \\
\hline
\end{tabular}

bronchial asthma in children. Moreover, $71.6 \%$ of PHC personnel had good knowledge regarding magnitude, definition and causes, risk factors (64.4\%), associated diseases (57.2\%), clinical picture (61.3\%), management $(59.8 \%)$, and prognosis $(76.8 \%)$. On the other hand, $57.7 \%$ of the PHC personnel had poor knowledge level about the role of exercise in bronchial asthma [Table 2].

[Figure 1] shows that $81.8 \%$ of the physicians and $52.7 \%$ of the nurses had good total knowledge level regarding the total aspects of bronchial asthma in children.

According to [Table 3], it was evident that physicians had higher mean knowledge score regarding all the components and the total knowledge scores of bronchial asthma in children and the differences were found to be statistically significant except for the knowledge about prognosis. The results of the logistic regression analysis 
of significant factors predicting knowledge level about bronchial asthma in children showed that the following factors were found to be independently and significantly associated with good knowledge level: Physicians (OR $=0.407,95 \%$ CI $=0.242-0.684)$, females (OR $=4.247,95 \% \mathrm{CI}=1.197-15.071)$, younger age $(\mathrm{OR}=1.144,95 \%$

\begin{tabular}{|c|c|c|c|c|c|}
\hline \multirow[t]{3}{*}{ Knowledge components } & \multicolumn{5}{|c|}{ Knowledge level } \\
\hline & \multicolumn{2}{|c|}{ Good } & \multicolumn{2}{|c|}{ Poor } & Total \\
\hline & No. & $\%$ & No. & $\%$ & No. $\%$ \\
\hline Total Knowledge score & 107 & 55.2 & 87 & 44.8 & 194100.0 \\
\hline $\begin{array}{l}\text { Magnitude, definition \& } \\
\text { causes }\end{array}$ & 139 & 71.6 & 55 & 28.4 & 194100.0 \\
\hline Risk Factors & 125 & 64.4 & 69 & 35.6 & 194100.0 \\
\hline Associated diseases & 111 & 57.2 & 83 & 42.8 & 194100.0 \\
\hline Role of Exercise & 82 & 42.3 & 112 & 57.7 & 194100.0 \\
\hline Clinical picture & 119 & 61.3 & 75 & 38.7 & 194100.0 \\
\hline Management & 116 & 59.8 & 78 & 40.2 & 194100.0 \\
\hline Prognosis & 149 & 76.8 & 45 & 23.2 & 194100.0 \\
\hline
\end{tabular}

\begin{tabular}{|c|c|c|c|c|c|}
\hline $\begin{array}{l}\text { Knowledge } \\
\text { Components }\end{array}$ & & $\begin{array}{l}\text { Physicians } \\
(n=44)\end{array}$ & $\begin{array}{l}\text { Nurses } \\
(n=150)\end{array}$ & $t$-test & $P$-value \\
\hline \multirow{2}{*}{$\begin{array}{l}\text { Total Knowledge } \\
\text { score }\end{array}$} & $\overline{\mathrm{X}}^{*}$ & 1.81 & 1.47 & 4.8 & 0.00 \\
\hline & $S D^{* *}$ & 0.39 & 0.50 & & \\
\hline \multirow{2}{*}{$\begin{array}{l}\text { Magnitude, } \\
\text { Definition \& Causes }\end{array}$} & $\bar{x}$ & 1.86 & 1.67 & 2.93 & 0.004 \\
\hline & SD & 0.34 & 0.47 & & \\
\hline \multirow[t]{2}{*}{ Risk Factors } & $\bar{x}$ & 1.77 & 1.606 & 2.20 & 0.031 \\
\hline & SD & 0.42 & 0.49 & & \\
\hline \multirow[t]{2}{*}{ Associated Diseases } & $\bar{x}$ & 1.75 & 1.52 & 2.96 & 0.004 \\
\hline & SD & 0.43 & 0.50 & & \\
\hline \multirow[t]{2}{*}{ Role of Exercise } & $\bar{x}$ & 1.61 & 1.36 & 2.96 & 0.003 \\
\hline & SD & 0.49 & 0.48 & & \\
\hline \multirow[t]{2}{*}{ Clinical picture } & $\bar{x}$ & 1.75 & 1.57 & 2.28 & 0.025 \\
\hline & SD & 0.43 & 0.49 & & \\
\hline \multirow[t]{2}{*}{ Management } & $x$ & 1.72 & 1.56 & 2.11 & 0.038 \\
\hline & SD & 0.45 & 0.49 & & \\
\hline \multirow[t]{2}{*}{ Prognosis } & $\bar{x}$ & 1.84 & 1.74 & 1.42 & 0.158 \\
\hline & SD & 0.36 & 0.43 & & \\
\hline
\end{tabular}

* Mean, ** Standard deviation
$\mathrm{CI}=1.007-1.299)$, and those with less than 5 years duration of work in PHC $(\mathrm{OR}=2.109,95 \% \mathrm{CI}=1.030-4.321),(P<0.001)$ [Table 4].

\section{DISCUSSION}

The majority of PHCCs personnel were young females. This is mainly due to the predominance of nurses who were mainly females, reflecting the usual pattern in KSA. Physicians in the sample were mainly general practitioners who had no post-graduate qualifications and no training in bronchial asthma. The total knowledge score of PHCCs personnel and the knowledge about causes and management of bronchial asthma were generally good. The results were in agreement with other studies among PHC physicians and nurses. ${ }^{[10,11,13,15-17]}$ A study of the level of knowledge about childhood asthma showed that general practitioners scored well in most questions but had some deficiencies particularly in distinguishing preventive therapy from symptom-relieving medication. ${ }^{[10]}$ Pediatric nurses in the previous study had poor knowledge of exerciseinduced asthma, which is similar to the result of the present study. Al-Kabba et al., in their study of primary care physicians knowledge about bronchial asthma using a true or false self-administered questionnaire, reported that only $39 \%$ of the of the 44 physicians passed the test as a whole, with $66 \%$ passed in general knowledge, $70 \%$ in diagnosis, $48 \%$ in classification of severity, and $59 \%$ in the management of asthma. ${ }^{[13]} \mathrm{A}$ study of the prevalence of asthma in Yanbu industrial city and two non-industrial villages in KSA reported

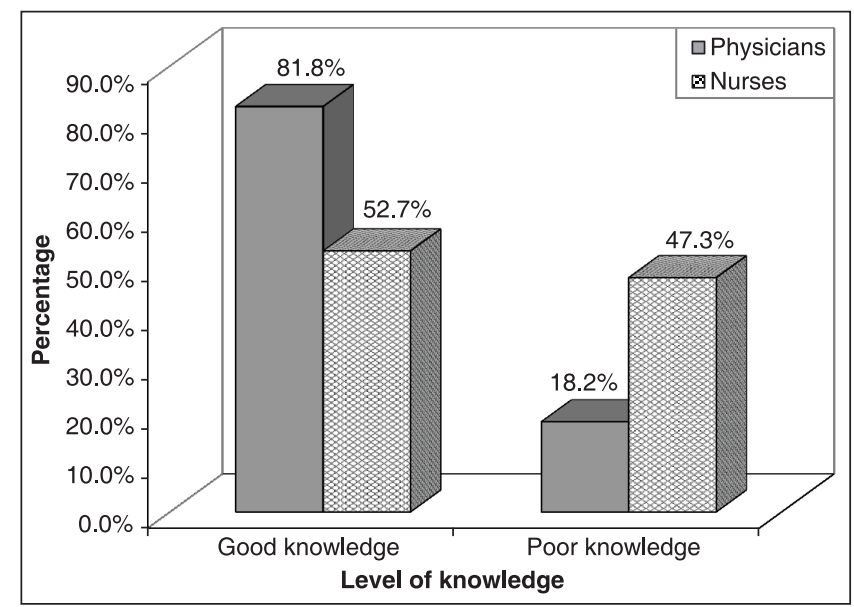

Figure 1: Distribution of PHC personnel according to their level of total knowledge score about bronchial asthma

\begin{tabular}{|c|c|c|c|c|c|c|}
\hline \multirow[t]{2}{*}{ Variables } & \multirow[t]{2}{*}{ B coefficient } & \multirow[t]{2}{*}{ S. E. of B } & \multirow[t]{2}{*}{$P$-value } & \multirow[t]{2}{*}{ O. R. } & \multicolumn{2}{|c|}{ 95\% Confidence interval of O. R. } \\
\hline & & & & & Lower & Upper \\
\hline Occupation & -0.899 & 0.265 & 0.001 & 0.407 & 0.242 & 0.684 \\
\hline Gender & 1.446 & 0.646 & 0.025 & 4.247 & 1.197 & 15.071 \\
\hline Age & 0.134 & 0.065 & 0.038 & 1.144 & 1.007 & 1.299 \\
\hline Duration of work in $\mathrm{PHC}$ & 0.746 & 0.366 & 0.041 & 2.109 & 1.030 & 4.321 \\
\hline Constant & -0.336 & 2.316 & - & - & - & - \\
\hline
\end{tabular}

Model $X_{(14)}^{2}=38.251, P<0.001$, 
a prevalence of physician-diagnosed asthma in the three areas of $13.9 \%, 2.2 \%$ and $13.7 \%$ respectively. ${ }^{[7]}$

Similar results were shown by Lageriov et al., study among 698 general practitioners in five European countries assessing their knowledge, attitudes, and prescribing behavior. It showed that most doctors were in agreement with guideline recommendations. ${ }^{[9]}$ In practice, however, the proportion of asthma patients receiving inhaled steroids varied almost two-fold, ranging 31\% in Germany to $58 \%$ in the Netherlands..$^{[9]}$

Our study was also in agreement with Coates et al., study among 127 South Australian general practitioners concerning knowledge and reported asthma management, ${ }^{[14]}$ which revealed deficiencies in their knowledge and management practices of asthma and suggest that ideal asthma management was not being attained.

In this study physicians had better total knowledge compared to nurses. This result was similar to Lemay et al., study who reported that $32 \%$ of pediatric residents, $12 \%$ of family medicine residents and $72 \%$ of pediatric nurses failed to identify all three main symptoms of asthma (wheezing, cough, dyspnea). ${ }^{[16]}$ In Lemay et al., study, 25\% of pediatric residents, $52 \%$ of family medicine residents and $81 \%$ of pediatric nurses were unable to name at least two preventive asthma medications. ${ }^{[1]]}$ However, another study in Aseer Region, Saudi Arabia, showed poor knowledge of PHC physicians on asthma care, where they got $37.7 \%$ of the total scoring of case scenarios on asthma care. ${ }^{[16]}$

In this study there were deficiencies in knowledge mainly concerning the role of exercise and management of asthma. Continuing medical education should focus on these areas especially for nurses who had unsatisfactory knowledge as shown by the significantly lower mean knowledge compared to physicians. Tomson et al., study reported that there were changes in knowledge, attitudes and actual practice of Swedish primary care physicians after intervention messages concerning management of bronchial asthma. ${ }^{[1]} \mathrm{A}$ similar study by Rovithis et al., demonstrated an improvement in knowledge of PHC physicians serving a rural population on the island of Crete after a one-day educational course on bronchial asthma clinical guidelines. ${ }^{[8]}$ These results stress the need for interventions in the form of frequent courses and continuing education to improve knowledge and practice of health care personnel about asthma and disease management.

In the present study, physicians had good knowledge in all aspects of bronchial asthma as shown by the logistic regression analysis. Female health care personnel were 4.2 times more likely to have good knowledge about bronchial asthma compared to males. This result was similar to Soyer et al., study in Turkey. ${ }^{[18]}$ They reported that even though self-perceived overall asthma knowledge did not differ between genders $(P=0.098)$, female physicians recorded more frequent use of inhaled steroids for chronic asthma $(3.72 \pm 0.08 \mathrm{vs}$. $3.43 \pm 0.07$, respectively, $P=0.006$ ) while male physicians scored higher than females for inhaled steroids for acute asthma (2.8 \pm 0.12 vs. $2.17 \pm 0.2$, respectively, $P=0.007$ ). Female physicians' scoring for 'symptom control' as the main aim of asthma management was higher than that of their male counterparts $(3.88 \pm 0.04$ vs. $3.65 \pm$ 0.06 , respectively, $P=0.002$ ).

In their study of clinicians adherence to asthma guidelines, Salama et al., showed that agreement with asthma guidelines was present in $76.2 \%$ of the studied physicians and there was positive significant correlation between qualification and knowledge, $(P<0.01)$, positive significant correlation between qualification and practice, $(P<0.01)$, and positive significant correlation between qualification and attitude, $(P<0.01) \cdot{ }^{[19]}$ In the current study, the fact that younger health care personnel and those with less than 5-years experience of work in PHCCs had significantly good knowledge which may possibly be due to their being newly graduated physicians with recent knowledge from their medical school studies. Nurses were still having some deficiencies in knowledge of bronchial asthma compared to physicians.

\section{CONCLUSIONS}

This study showed that the majority of health care personnel had good knowledge about bronchial asthma. However, there are still some deficiencies about management and the role of exercise in asthma. Being a physician, a female, of young age, and with less years of work in PHCCs were significantly associated with good knowledge of bronchial asthma. It is recommended that both physicians and nurses should be informed and continuously reminded of the diagnosis and management of bronchial asthma according to the National Guidelines. This can be done through continuing medical education in the form of seminars, workshops and clinical teaching using patients with asthma. In addition, assessment of actual practice of physicians and nurses is greatly needed so that knowledge can be reflected on better patient care.

\section{Limitations of the study}

This study depends on self-reporting which might have resulted in over- or under-reporting of some aspects of asthma knowledge. This was a cross-sectional study done at a point in time. Therefore, cause and effect cannot be definitely assumed regarding factors predicting knowledge of asthma. Further studies on the effects of health care personnel practice in improving care of patients with asthma are needed.

\section{REFERENCES}

1. Neri M, Spanevello A. Chronic bronchial asthma from challenge to treatment: Epidemiology and social impact. Thorax 2000;55:S57-8.

2. Variations in the prevalence of respiratory symptoms, self-reported asthma attacks, and use of asthma medication in the European Community Respiratory Health Survey (ERCHS). Eur Respir J 1996;9:687-95.

3. World Health Organization. Asthma Fact sheet N 307. WHO; 2011.

4. Al-Frayh A, Bener A, Al-Jawadi TQ. Prevalence of asthma among Saudi school children. Saudi Med J 1992;13:521-4.

5. Al Frayh AR, Shakoor Z, Gad El Rab MO, Hasnain SM. Increased prevalence of asthma in Saudi Arabia. Ann Allergy Asthma Immunol 2001;86:292-6. 
6. Hijazi N, Abalkhail B, Seaton A. Asthma and respiratory symptoms in urban and rural Saudi Arabia. Eur Respir J 1998;12:41-4.

7. al-Shairi A, al-Dawood K. Schoolboys in urban industrial environments: Are they at increased risk of bronchial asthma? East Mediterr Health $\mathrm{J}$ 1999;5:657-63.

8. Rovithis E, Lionis C, Schiza SE, Bouros D, Karokis A, Vlachonikolis I, et al. Assessing the knowledge of bronchial asthma among primary health care physicians in Crete: A pre- and post-test following an educational course. BMC Med Educ 2001;1:2.

9. Lagerløv $P$, Veninga CC, Muskova M, Hummers-Pradier E, Stålsby Lundborg $\mathrm{C}$, Andrew $\mathrm{M}$, et al. Asthma management in five European countries: Doctors' knowledge, attitudes and prescribing behaviour. Drug Education Project (DEP) group. Eur Respir J 2000;15:25-9.

10. Henry RL, Fitzclarence CA, Henry DA, Cruickshank D. What do health care professionals know about childhood asthma? J Paediatr Child Health 1993;29:32-5.

11. Tomson Y, Hasselström J, Tomson G, Aberg H. Asthma education for Swedish primary care physicians--a study on the effects of "academic detailing" on practice and patient knowledge. Eur J Clin Pharmacol 1997;53:191-6.

12. Gharagozlou $M$, Abdollahpour $\mathrm{H}$, Moinfar $\mathrm{Z}$, Bemanian $\mathrm{MH}$, Sedaghat $\mathrm{M}$. A survey of pediatricians' knowledge on asthma management in children. Iran J Allergy Asthma Immunol 2008;7:85-90.

13. Al-Kabbaa AF, Al-Shamrani KM, Salih MA. Does the management of bronchial asthma by family physicians meet standards of the national protocol? J Fam Commu Med 2002;9:21-5.
14. Coates JR, Steven ID, Beilby J, Coffey G, Litt JC, Wagner C. Knowledge of and reported asthma management among South Australian general practitioners. Br J Gen Pract 1994;44:123-6.

15. Ahmed Y, Anjum Q, Qureshi F, Qureshi AF. Assessment of physicians understanding of asthma guidelines in a tertiary care hospital. J Pak Med Assoc 2004;54:530-1.

16. Lemay JF, Moore SI, Zegray M, Ducharme FM. What do nurses and residents know about childhood asthma? Can Respir J 1999;6:417-22.

17. Abudahish A, Bella H. Primary care physicians perceptions and practices on asthma care in Aseer region, Saudi Arabia. Saudi Med J 2006;27 333-7.

18. Soyer OU, Civelek E, Sekerel BE. Physicians' perception of childhood asthma in Turkey: More appropriate practice among female physicians. BMC Health Serv Res 2008;8:155.

19. Salama AA, Mohammed AA, El Okda el SE, Said RM. Quality of care of Egyptian asthmatic children: Clinicians adherence to asthma guidelines. Ital J Pediatr 2010;36:33.

How to cite this article: Taha AZ, Sabra AA, Al Hamed JH. Knowledge about childhood bronchial asthma among primary health care personnel in eastern Saudi Arabia. Int J Med Public Health 2014;4:222-6.

Source of Support: Nil, Conflict of Interest: None declared. 